Research Article

\title{
Study on Reasonable Layout of Upper Protective Layer for Prevention Rock Burst under Coal Seam Group with Close Quarters Conditions
}

\author{
Hui-Wu Jin ${ }^{1}$ and Zeng-Qiang Yang $\mathbb{D}^{1,2}$ \\ ${ }^{1}$ School of Transportation Engineering, Jiangsu Vocational Institute of Architectural Technology, Xuzhou, Jiangsu 221116, China \\ ${ }^{2}$ State Key Laboratory of Coal Resources and Mine Safety, China University of Mining \& Technology, Xuzhou, \\ Jiangsu 221116, China
}

Correspondence should be addressed to Zeng-Qiang Yang; zengqiang5@126.com

Received 14 July 2021; Accepted 10 August 2021; Published 18 August 2021

Academic Editor: Antonio Giuffrida

Copyright (c) 2021 Hui-Wu Jin and Zeng-Qiang Yang. This is an open access article distributed under the Creative Commons Attribution License, which permits unrestricted use, distribution, and reproduction in any medium, provided the original work is properly cited.

\begin{abstract}
To study the reasonable layout of upper protective layer for the prevention rock burst under coal seam group with close quarters conditions, a panel 3203 that belong to Zhongxing Colliery is taken as a typical engineering background. By means of on-site survey, theoretical analysis, numerical simulation, and on-site industrial applications, the reasonable layout of upper protective layer for prevention rock burst is studied. The results show that the overall stress environment of the floor under gob of upper protective layer is good, and the overall stress environment of the floor under the upper side of gob is also good, but the overall stress environment of the floor under the lower side of gob is bad. According to numerical simulation results, an L-shaped stress superposition area is formed in the lower end of panel 3203 under the original layout scheme conditions, and the maximum stress concentration coefficient is about 2.8 in stage I and 4.0 in stage II. A new stress superposition area is formed at the middle to lower end part of advance mining face of panel 3203 for the stage II under the optimal layout scheme conditions, and the maximum stress concentration coefficient is about 2.4; the original L-shaped stress superposition area is gone due the transfer and release of stress, and the optimal layout scheme has a very significant effect on the prevention and control of the subsequent rock burst accidents; the monitoring results of working resistance of hydraulic supports and surrounding rock deformation indicate that the overall pressure relief of the surrounding rock in advanced segment of 3205 tailgate can be effectively realized. The study conclusions provide theoretical foundation and a new guidance for preventing rock burst with similar engineering geological conditions.
\end{abstract}

\section{Introduction}

Rock burst is a typical dynamic disaster that often occurs in deep mining activities, and its obvious characteristic is the process of instant energy release that accumulates in high stress concentration area around the mining space [1-3]. Coal and gas outburst is also a typical dynamic disaster in deep mining activities, and it is caused by the poor permeability of coal seam under high stress environment. When the gas accumulates to a certain extent in the coal seam, it is easy to have a serious accident under the action of higher gas pressure $[4,5]$. Therefore, when a coal seam with high gas accumulation and large burial depth, it is easy to induce dynamic disasters under the mining period.

In recent years, many scholars and experts have studied the problems of high gas and high ground stress. Dou et al. [6] used microseismic monitoring techniques to study the microseismic energy evolution law under dynamic and static combined load, and the theory of dynamic and static load superposition principle was systematically put forward; Pan et al. $[7,8]$ put forward that the occurrence mechanism of rock burst can be divided into three stages, namely start-up stage of rock burst, transfer stage of rock burst, and occurrence stage of rock burst; Zhao et al. [9] studied the 
loading characteristics and rock bust instability mechanism of gob-side roadway in deep mining and revealed the "three load" superimposed induced rock burst mechanism of gobside roadway under lateral static load, advanced static load, and disturbed dynamic load of gob; Jiang et al. [10] put forward that roadway excavation along gob can effectively improve the stress environment of surrounding rock of gobside roadway, and thus reduce the maintenance cost of roadway and prevent rock burst accidents; Zhu et al. [11] discussed the influence of coal pillar width on rock burst instability and mine earthquake, and the reasonable design basis of coal pillar width based on the cooperative control of rock burst and mine earthquake was proposed. It can be seen that there are few literatures on the prevention and control mechanism of rock burst caused by mining of upper protective layer. In many literature studies [12-14], the upper protective layer mining, as a dominating method for preventing coal and gas outburst, is generally adopted in highly gassy coal mines. Therefore, it is necessary to study the influence mechanism of upper protective layer mining on floor and lower coal seam.

Combined with the geological conditions of panel 3203 in Zhongxing Colliery, this paper theoretically calculates and analyzes the influence of the gob of upper protective layer on the stress disturbance of the floor under the original layout scheme and optimizes the layout scheme of the panel of upper protective layer through numerical simulation and then carries out the on-site industrial applications in panel 3205. The on-site mine pressure monitoring results show that the optimized layout scheme of the panel of upper protective layer has a good control effect on the surrounding rock deformation of the gob-side roadway in advanced segment and improves the stress environment of the surrounding rock, which provides a reference and guidance for the reasonable design of the panel of upper protective layer under the coal seam group with similar close quarters conditions.

\section{General Situation of Geology}

2.1. Mining and Engineering Geological Conditions. Zhongxing Colliery, which is located in Jiaocheng county, Shanxi Province, is a modernization coal mine with an annual capacity of 2 million tons. This mine belongs to Shanxi Fenxi Mining Industry Group Co., Ltd. At present, the fully mechanized panel 3203 is in the mining stage, and this panel is located in the north wing of the third mining zone. The size of panel 3203 is $190 \mathrm{~m}$ wide along inclination and $1595 \mathrm{~m}$ long along strike, and the main mineable coal seam of this panel is seam No.2. The thickness of seam No.3 is about $1.5 \sim 2.4 \mathrm{~m}$, and its average thickness is $2.2 \mathrm{~m}$, which belong to medium thick coal seam. The dip angle of seam No. 2 is about $15^{\circ} \sim 24^{\circ}$, and its average dip angle is $18^{\circ}$, which belongs to gently inclined coal seam. As the ground level and underground working face level of panel 3203 are about $+1315 \sim+1576 \mathrm{~m}$ and $+708 \sim+780 \mathrm{~m}$, respectively, which means that the average burial depth of panel 3203 is about $700 \mathrm{~m}$, and the corresponding in situ stress is relatively large during the mining period. There is another coal seam above the seam No.2, which is named seam No.1. The seam No.1 can be seen as an upper protective layer of the seam No.2. The thickness of seam No.1 is about $0.7 \sim 1.6 \mathrm{~m}$, and its average thickness is $1.3 \mathrm{~m}$. The vertical interval between seam No.1 and seam No.2 is about $8.2 \sim 12.4 \mathrm{~m}$, and its average vertical spacing is $10.3 \mathrm{~m}$, which belongs to the mining mode of coal seam group with close quarters. A panel that is placed in the upper protective layer can be used to deal with the gas problem and alleviate the in situ stress problem. The plane position relation of panel 3203 is shown in Figure 1.

According to Figure 1, it can be seen that the panel of upper protective layer is almost directly above the middle of panel 3203. In this arrangement, the 3203 tailgate is a gobside entry, and a $2.5 \mathrm{~m}$ wide filling wall is reserved to protect this gob-side entry.

\subsection{Mine Pressure of 3203 Tailgate}

2.2.1. Mine Pressure Behaviors of Surrounding Rock. With the panel 3203 mining, when it is in the influence range of the panel of upper protective layer, although the panel of upper protective layer can reduce the risk of panel 3203 affected by gas disaster, it has no effect on improving the stress environment of the surrounding rock and even the surrounding rock stress environment becomes worse. According to Figure 1, it can be seen that 3203 tailgate is a gob-side entry, and it will be affected by abutment pressure of the side direction of gob 3201. During the mining period of panel 3203, the advanced segment of 3203 tailgate will also be affected by the superposition of advanced abutment stress, and the surrounding rock stress environment of 3203 tailgate will deteriorate further. Based on dynamic and static load superposition principle, the advanced segment of 3203 tailgate is easy to induce rock burst accident. Figure 2 shows the surrounding rock failure of the advanced segment about 3203 tailgate on-site.

Based on the field investigation results about advanced segment of 3203 tailgate, it can be seen that the roof is mainly affected by horizontal stress and appears to be severely fractured, as shown in Figure 2(a). In this case, the roof is easy to cave and forms a roof-fall accident; the solid-coal rib of 3203 tailgate is mainly affected by vertical stress, which is caused by the superposition of abutment pressure of side direction and advanced abutment stress, and it suffers from serious extrusion deformation, as shown in Figure 2(b). In this case, the anchor bolts and anchor cables in coal body are easy to pull apart; the floor are also affected by the superposition of horizontal stress and vertical stress, and it is easy to form serious heaving floor, as shown in Figure 2(c). In this case, the floor will become very uneven, and even the local floor deformation is large, which will seriously affect the production and transportation demand of 3203 tailgate. Figure 2(d) shows a rock burst accident that happened in the advanced segment of 3203 tailgate, and this serious accident caused a sudden influx of coal-rock mass into the roadway. In this case, the working face was unable to work safely, and several miners were injured at the same time. 


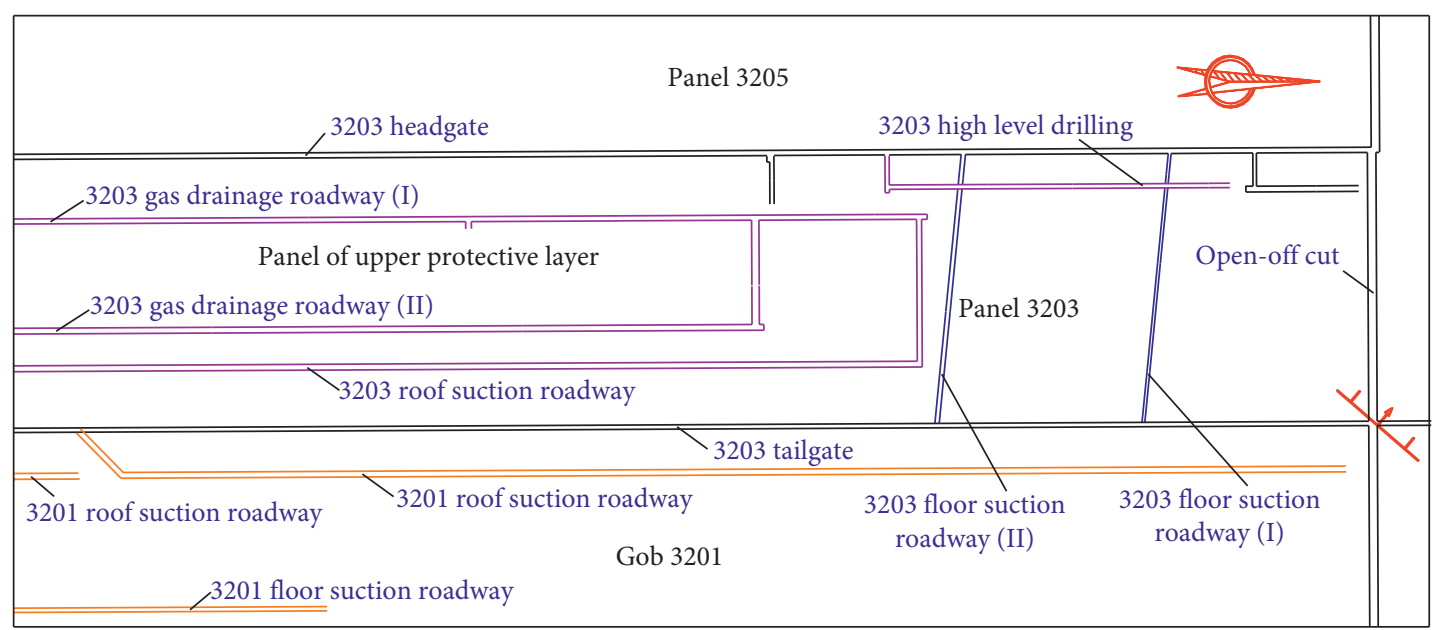

FIgURE 1: The plane position relation of panel 3203.

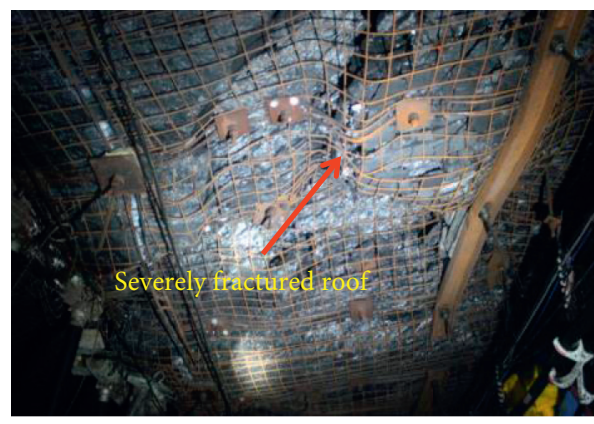

(a)

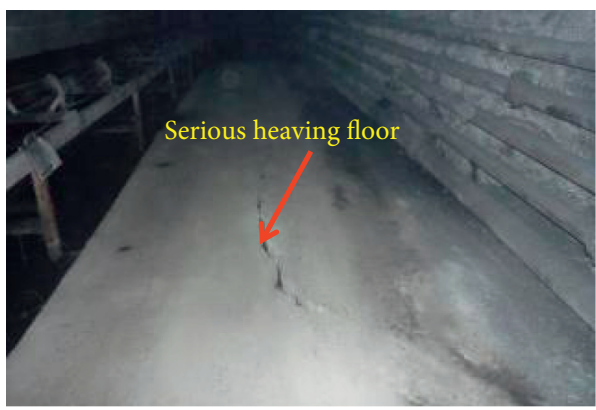

(c)

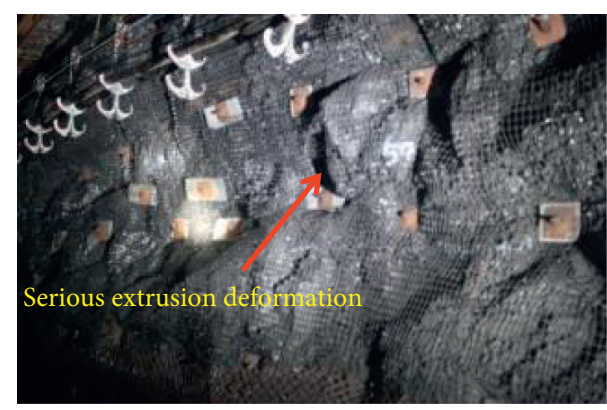

(b)

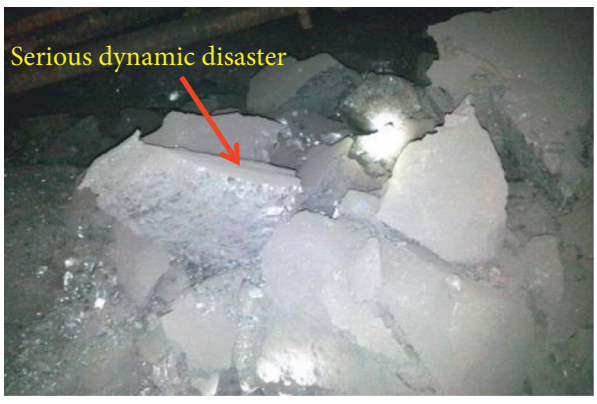

(d)

Figure 2: The surrounding rock failure of advanced segment about 3203 tailgate on-site. (a) Typical failure of roof, (b) typical failure of solid-coal rib; (c) typical failure of floor I, (d) typical failure of floor (II).

2.2.2. Mine Pressure Behaviors of Filling Wall. As the 3203 tailgate is a gob-side entry, it is preserved by a filling wall. The filling wall is made of paste filling materials, and the paste filling materials are made up of $36 \%$ medium sand, $35 \%$ blinding, $14 \%$ cement, $8 \%$ mixing water, $6 \%$ pulverized coal ash, and $1 \%$ admixture. This paste filling materials have good fluidity and gel resistance, and its mass concentration is more than $85 \%$.

To test the complete mechanical properties of the filling wall made of paste filling materials, the standard specimens were made for uniaxial compression test. The abrasive tools were cylindrical, and they were made of PVC pipes. The inner diameter of these abrasive tools was $50 \mathrm{~mm}$, and height of these abrasive tools was $100 \mathrm{~mm}$. When the paste filling materials were prepared, filled them into the abrasive tools compactly after the inner wall of these PVC pipes were treated by lubricating oil and then maintained for a period of time. The maintenance time can be divided into 1 day, 3 days, 5 days, 7 days, 10 days, 13 days, and 16 days, respectively, and three standard specimens were prepared at each maintenance time. After demoulding, the mechanical properties were tested on an MTS 815 servo system. Considering that the load on the filling wall increased gradually with the mining process in practice, to test the quasi-static mechanical properties of these specimens, the axial compression rate was selected as $0.01 \mathrm{~mm} / \mathrm{min}$ [15]. The ultimate 
compressive strength of standard specimens is shown in Figure 3.

According to Figure 3, a total of 21 standard specimens need to be tested for ultimate compressive strength, and the laboratory test result of each standard specimen is shown in Figure 3(a). The average ultimate compressive strength of three standard specimens at each maintenance time can be calculated, as shown in Figure 3(b). It can be seen from Figure 3(b) that when the maintenance time is $1 \sim 7$ days, the average ultimate compressive strength of standard specimens increases significantly with the increase in maintenance time; when the maintenance time is $7 \sim 13$ days, the average ultimate compressive strength of standard specimens increases slowly with the increase in maintenance time; when the maintenance time is 13 16 days, the average ultimate compressive strength of standard specimens basically not increases and gradually stabilized to $14.7 \mathrm{MPa}$. It can be seen that when the maintenance time is 13 days, the average ultimate compressive strength of standard specimens goes up to $14.5 \mathrm{MPa}$, and it has accounted for $98.6 \%$ of the final strength, which means that the strength increasing efficiency is the optimal when the maintenance time is 13 days. That is to say, the strength of filling wall can basically reach the final strength value and meet the production needs when the maintenance time is 13 days. Therefore, the best maintenance time of filling wall is finally determined to be 13 days on-site.

Three observation stations with an interval of $50 \mathrm{~m}$ were arranged in the advanced segment of 3203 tailgate under the influence of gob of upper protective layer. The convergence of surrounding rock was measurand by nails that were fixed in the middle position of floor, roof and two ribs, and the bearing stress of filling wall was measurand by stress detectors that were fixed in the middle positon of the filling wall. After averaging the observation data, the mine pressure observation results of 3203 tailgate are shown in Figure 4.

It can be seen from Figure 4 that the convergence of surrounding rock about 3203 tailgate tends to be stable after 30 days. At this time, the maximum convergence of roof to floor is $801 \mathrm{~mm}$, and the maximum convergence of two ribs is $623 \mathrm{~mm}$. The whole deformation of surrounding rock is serious, which seriously hinders the safe and efficient mining of panel 3203. At the same time, the observation data about bearing stress of filling wall increase to a maximum value of 13.5 $\mathrm{MPa}$ when the filling wall is retained for 16 days. It can be seen that the ratio between the maximum bearing stress and the ultimate compressive strength of the filling wall is as high as 0.93 , and the filling wall has poor stress environment and is prone to instability under the action of high bearing stress.

Therefore, it is necessary to redesign the layout of the panel of upper protective layer, then the stress environment of surrounding rock about 3203 tailgate is improved.

\section{Stress Analysis of Floor under the Mining Influence of Upper Protective Layer}

3.1. Establishment of Mechanical Model. Assuming that the dip angle of upper protective layer is $\alpha$, when a panel is formed in the upper protective layer, and then abutment pressure of side direction will be formed on both sides of the gob. The abutment pressure of side direction will lead to the change of stress environment in the floor of upper protective layer. The simplified mechanical model of abutment pressure of side direction on both sides of gob after mining is shown in Figure 5.

According to Figure 5, it can be seen that the abutment pressure of side direction can be decomposed into a vertical stress perpendicular to the upper protective layer and a transverse stress parallel to the upper protective layer, in which the vertical stress will directly affect the stress environment of the floor. Assuming that the buried depth of entry \#1 on the upper side of the gob is $H_{1}$, the buried depth of entry \#2 on the lower side of the gob is $\mathrm{H}_{2}$, the average bulk density of overlying rock is $\gamma$, and the peak stress concentration factor of the upper and lower sides is $k_{b}$ and $k_{d}$. A coordinate system mon is established on the upper side of the gob, and the vertical stress at the coordinate origin $o$ is determined as $\sigma_{n 1}$, which increases linearly to a peak stress $\sigma_{n 2}$ at point $b$ and then reduce to the original rock stress $\sigma_{n 3}$ at point $c$. The specific expression of vertical stress at each inflection point on the upper side is shown as

$$
\left\{\begin{array}{l}
\sigma_{n 1}=k_{1} \gamma H_{1} \cos \alpha \\
\sigma_{n 2}=k_{b} \gamma\left(H_{1}-S_{1} \sin \alpha\right) \cos \alpha \\
\sigma_{n 3}=\gamma\left(H_{1}-\left(S_{1}+S_{2}\right) \sin \alpha\right) \cos \alpha
\end{array}\right.
$$

where $k_{1}$ is the stress concentration factor of abutment pressure of side direction on the upper side at point $o ; S_{1}$ is the projector distance between points $o$ and $b$ along inclination, $\mathrm{m} ; \mathrm{S}_{2}$ is the projector distance between points $b$ and $c$ along inclination, $\mathrm{m}$.

Similarly, a coordinate system $x o z$ is established on the lower side of the gob, and the vertical stress at the coordinate origin $o$ is determined as $\sigma_{z 1}$, which increases linearly to a peak stress $\sigma_{z 2}$ at point $d$ and then reduce to the original rock stress $\sigma_{z 3}$ at point $e$. The specific expression of vertical stress at each inflection point on the lower side is shown as

$$
\left\{\begin{array}{l}
\sigma_{z 1}=k_{2} \gamma H_{2} \cos \alpha \\
\sigma_{z 2}=k_{d} \gamma\left(H_{2}+S_{3} \sin \alpha\right) \cos \alpha \\
\sigma_{z 3}=\gamma\left(H_{2}+\left(S_{3}+S_{4}\right) \sin \alpha\right) \cos \alpha
\end{array}\right.
$$

where $k_{2}$ is the stress concentration factor of abutment pressure of side direction on the lower side at point $o ; S_{3}$ is the projector distance between points $o$ and $d$ along inclination, $\mathrm{m} ; S_{4}$ is the projector distance between points $d$ and $e$ along inclination, $\mathrm{m}$.

According to the theory of elastic mechanics $[16,17]$, assuming that the coal-rock mass is a homogeneous isotropic space semi-infinite plane body, the influence of a small vertical pressure load $q \mathrm{~d} u$ of the abutment pressure of side direction on both sides of the gob for any point in floor, such as point $N(m, n)$ or $M(x, z)$, can be expressed as 


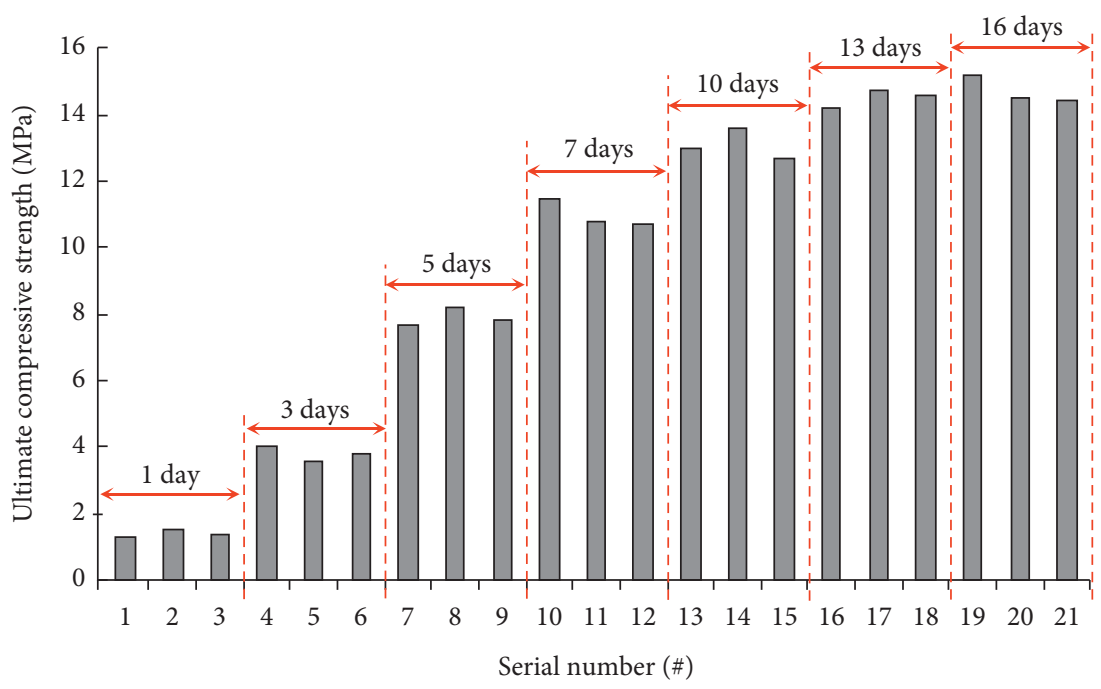

Standard specimens

(a)

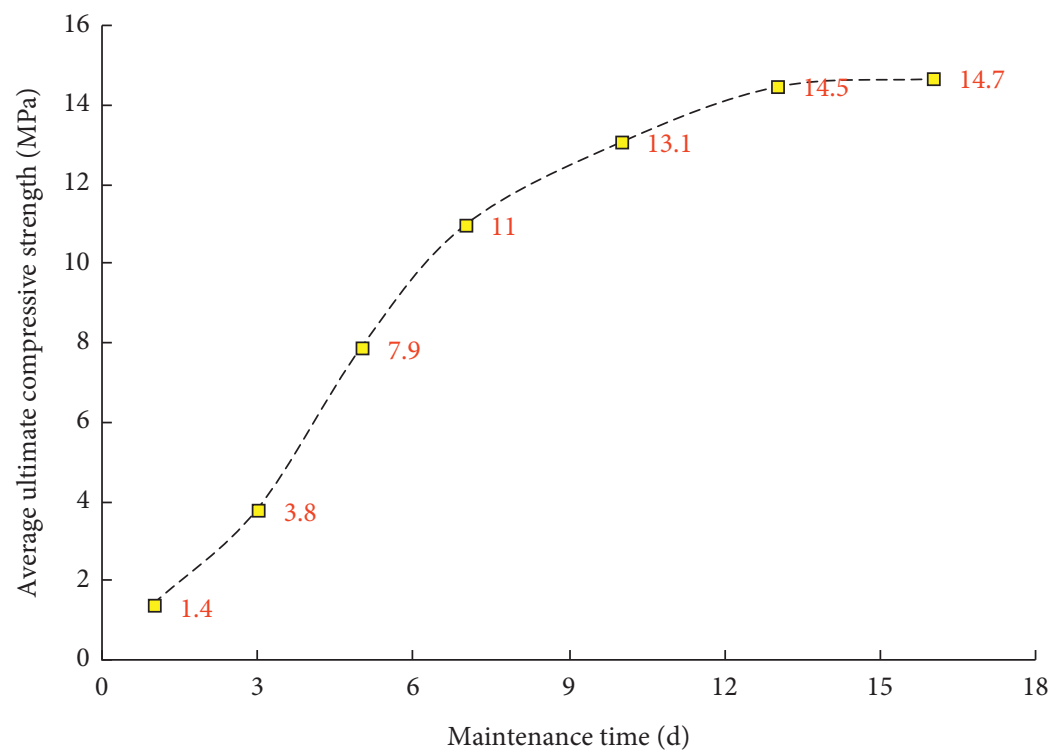

-ロ- Standard specimens

(b)

FIGURE 3: Ultimate compressive strength of standard specimens. (a) Laboratory test results, (b) average calculation results.

$$
\left\{\begin{array}{l}
\mathrm{d} \sigma_{n}=\frac{2 q \mathrm{~d} u}{\pi} \frac{n^{3}}{\left[(x-u)^{2}+n^{2}\right]^{2}}, \\
\mathrm{~d} \sigma_{z}=\frac{2 q \mathrm{~d} u}{\pi} \frac{z^{3}}{\left[(x-u)^{2}+z^{2}\right]^{2}},
\end{array}\right.
$$

pressure of side direction of $o b$ section, $b c$ section, $o d$ section and de section can be calculated by integral form:

where $\mathrm{d} \sigma_{n}$ is the vertical pressure caused by a small vertical pressure load $q \mathrm{~d} u$ at point $N(m, n)$ in floor, MPa; $\mathrm{d} \sigma_{z}$ is the vertical pressure caused by a small vertical pressure load $q \mathrm{~d} u$ at point $M(x, z)$ in floor, $\mathrm{MPa}$.

According to the abutment pressure of side direction formed on the upper or lower side of the gob, the abutment 


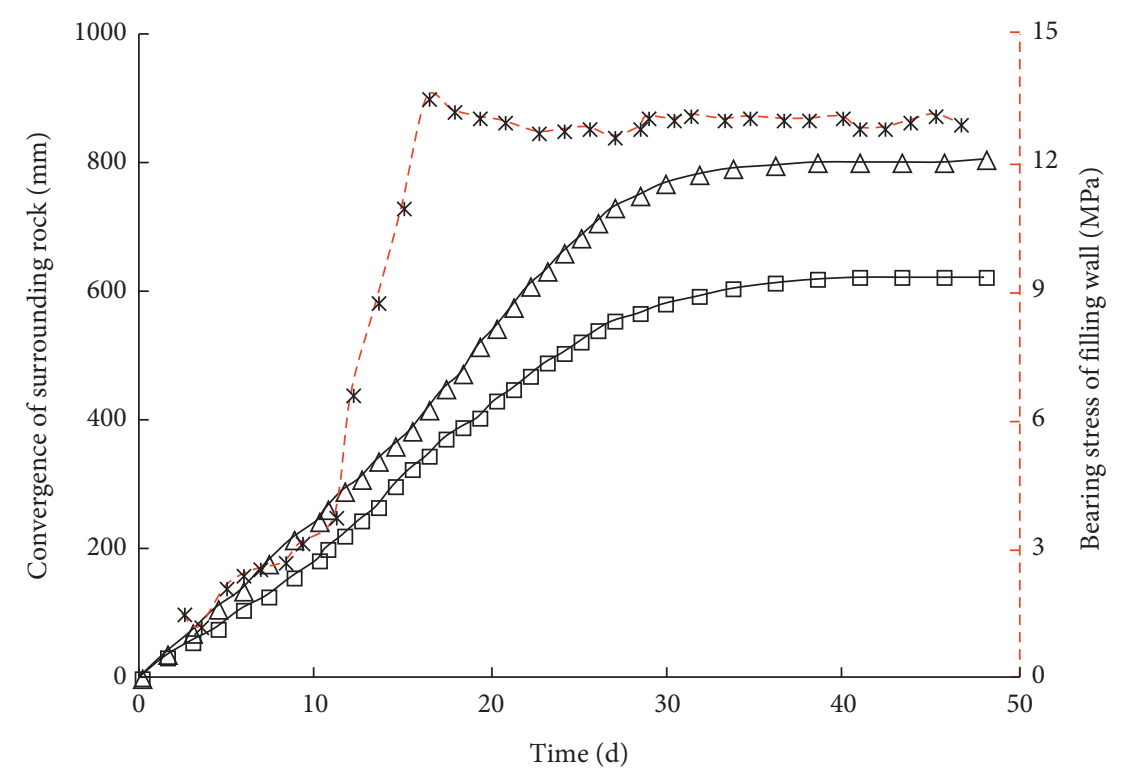

$\triangle$ Two ribs

$\square$ Roof to floor

-*- Filling wall

FIGURE 4: Mine pressure observation results of 3203 tailgate.

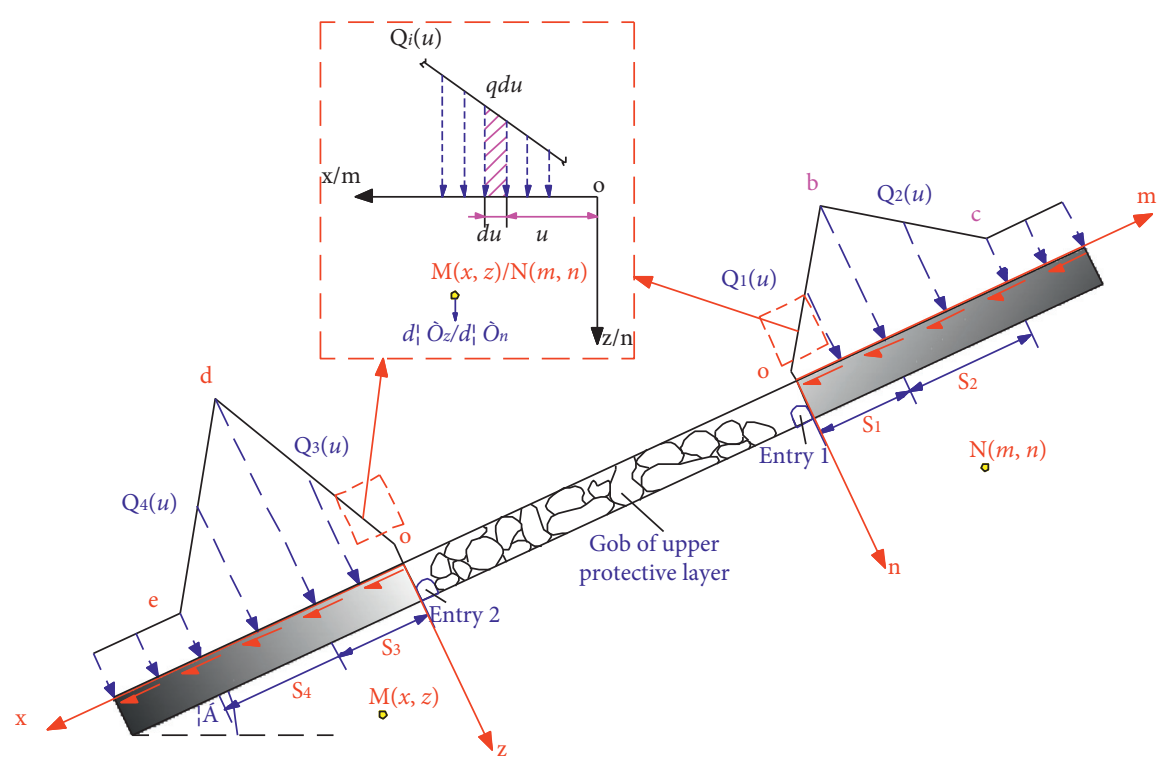

FIgURE 5: Simplified mechanical model of abutment pressure of side direction on both sides of gob.

where $Q_{1}(u)$ is the abutment pressure of side direction expression within the range $\left[0, S_{1}\right), \mathrm{MPa} ; Q_{2}(u)$ is the abutment pressure of side direction expression within the range $\left[S_{1}, S_{2}\right), \mathrm{MPa} ; Q_{3}(u)$ is the abutment pressure of side direction expression within the range $\left[0, S_{3}\right), \mathrm{MPa} ; Q_{4}(u)$ is the abutment pressure of side direction expression within the range $\left[S_{3}, S_{4}\right), \mathrm{MPa}$.

In coordinate system, mon and coordinate system xoz, applying equation (3) to integrate the abutment pressure of side direction of $o b$ section, $b c$ section, $o d$ section and $d e$ 
section, and then substituting into equation (4), the vertical stress at any point in the floor of the upper and lower sides of gob can be obtained:

$$
\left\{\begin{array}{l}
\sum \sigma_{n}=\sigma_{o b}+\sigma_{b c}=\frac{2}{\pi}\left(\int_{0}^{S_{1}} \frac{Q_{1}(u) n^{3} \mathrm{~d} u}{\left[(x-u)^{2}+n^{2}\right]^{2}}+\int_{S_{1}}^{S_{2}} \frac{Q_{2}(u) n^{3} \mathrm{~d} u}{\left[(x-u)^{2}+n^{2}\right]^{2}}\right), \\
\sum \sigma_{z}=\sigma_{o d}+\sigma_{d e}=\frac{2}{\pi}\left(\int_{0}^{S_{3}} \frac{Q_{3}(u) z^{3} \mathrm{~d} u}{\left[(x-u)^{2}+z^{2}\right]^{2}}+\int_{S_{3}}^{S_{4}} \frac{Q_{4}(u) z^{3} \mathrm{~d} u}{\left[(x-u)^{2}+z^{2}\right]^{2}}\right),
\end{array}\right.
$$

where $\sum \sigma_{n}$ is the vertical stress at any point in the floor of the upper side of gob, $\mathrm{MPa} ; \sum \sigma_{z}$ is the vertical stress at any point in the floor of the lower side of gob, MPa.

In the known dip angle of upper protective layer $(\alpha)$, the buried depth of entry \#1 and entry \#2 $\left(H_{1}\right.$ and $\left.H_{2}\right)$, the average bulk density of overlying rock $(\gamma)$, the peak stress concentration factor of the upper and lower sides $\left(k_{b}\right.$ and $\left.k_{d}\right)$, and the projector distance of two adjacent inflection points along inclination $\left(S_{1}, S_{2}, S_{3}\right.$, and $\left.S_{4}\right)$, the contour map of vertical stress in the floor of upper side of gob can be drawn by solving equation (5).

3.2. Stress Bearing Analysis of Floor. Taking the upper protective layer of panel 3203 as the engineering background, the average bulk density of overlying rock is taken as $2.5 \mathrm{kN} /$ $\mathrm{m}^{3}$, the dip angle of upper protective layer is taken as $18^{\circ}$, and the buried depth of entry $\# 1$ and entry $\# 2$ is $362 \mathrm{~m}$ and $392 \mathrm{~m}$, respectively. According to the engineering experience, the peak stress concentration factor of the upper and lower sides is 1.65 and 1.05, respectively, and the projector distance between points $o$ and $b$, between points $b$ and $c$, between points $o$ and $d$, and between points $d$ and $e$ along inclination is $25 \mathrm{~m}, 20 \mathrm{~m}, 30 \mathrm{~m}$, and $25 \mathrm{~m}$, respectively. By substituting the specific parameter values into equation (5), and then the contour map of vertical stress in the floor of gob of upper protective layer can be drawn by using the Mathematica12.3 software (Chinese version), as shown in Figure 6.

It can be seen from Figures 6(a) and 6(b) that the overall stress environment of the floor under the gob of upper protective layer is good, and the vertical stress is kept within 4.0 MPa at the depth of $10.3 \mathrm{~m}$ in the floor, which is far less than the original rock stress of $9.3 \mathrm{MPa}$, indicating that the gob of upper protective layer plays a significant role in improving the stress environment of the floor, marking the overall stress value of the floor in this area smaller. It can be seen from Figure 6(a) that the overall stress environment of the floor under the upper side of gob is good, and the vertical stress $\left(\sum \sigma_{n}\right)$ is kept within $7.5 \mathrm{MPa}$ at the depth of $10.3 \mathrm{~m}$ in the floor, which is less than the original rock stress of 10.1 MPa, indicating that the gob of upper protective layer can improve the stress environment of the floor, making the overall stress value of the floor in this area smaller. However, it can be seen from Figure 6(b) that the overall stress environment of the floor under the lower side of gob is bad, the vertical stress $\left(\sum \sigma_{z}\right)$ is greater than $13.5 \mathrm{MPa}$ at the depth of $10.3 \mathrm{~m}$ in the floor, which is larger than the original rock stress of $10.1 \mathrm{MPa}$, indicating that the gob of upper protective layer has a great influence on the change of stress environment in floor and then has a great influence on the stress environment of surrounding rock during the driving and retaining of gob-side entry in this area, which is easy to cause serious mine pressure behaviors. The field observation results of 3203 tailgate in Figure 2 also verify the correctness of this theoretical calculation and analysis. Therefore, it is necessary to optimize the position of panel of upper protective layer above panel 3203.

\section{Numerical Simulation Analysis of Reasonable Arrangement of Panel of Upper Protective Layer}

4.1. Establishment of a Flac ${ }^{3 D}$ Model. According to the relative position relation of panel 3203 and its panel of upper protective layer shown in Figure 1, and combined with the relevant geological exploration borehole histogram data, a $3 \mathrm{D}$ model is established by Flac ${ }^{3 \mathrm{D}}$ software. The size of this $3 \mathrm{D}$ model is long $\times$ wide $\times$ height $=450 \mathrm{~m} \times 430 \mathrm{~m} \times 130 \mathrm{~m}$. In this $3 \mathrm{D}$ model, the width of panel 3203 along inclination is $190 \mathrm{~m}$, and the width of panel of upper protective layer along inclination is $120 \mathrm{~m}$. The size of 3203 tailgate is length $\times$ height $=4200 \mathrm{~mm} \times 2500 \mathrm{~mm}$, and the size of 3203 headgate is length $\times$ height $=5000 \mathrm{~mm} \times 3000 \mathrm{~mm}$. The width of filling wall of 3203 tailgate is $2.5 \mathrm{~m}$, and the dip angle of coal seam and strata is set to $18^{\circ}$. The $3 \mathrm{D}$ model is established as shown in Figure 7.

The horizontal and vertical displacement constraints are applied to the boundary of this 3D model, and the equivalent uniform load of $15.3 \mathrm{MPa}$, which is calculated by the product of buried depth of upper surface of this model $(610 \mathrm{~m})$ and average bulk density of overlying rock $\left(2.5 \mathrm{kN} / \mathrm{m}^{3}\right)$, is applied to the upper surface of the model. The Mohr-Coulomb constitutive model is used to build this $3 \mathrm{D}$ model, and the acceleration of gravity is set to $10.0 \mathrm{~m} / \mathrm{s}^{2}$. According to the in situ stress test results, the coefficient of horizontal pressure is defined as 1.3. The coal seam and strata assignment parameters of this $3 \mathrm{D}$ model are shown in Table 1.

These assignment parameters in Table 1 are obtained by testing the mechanical properties of coal and rock standard 


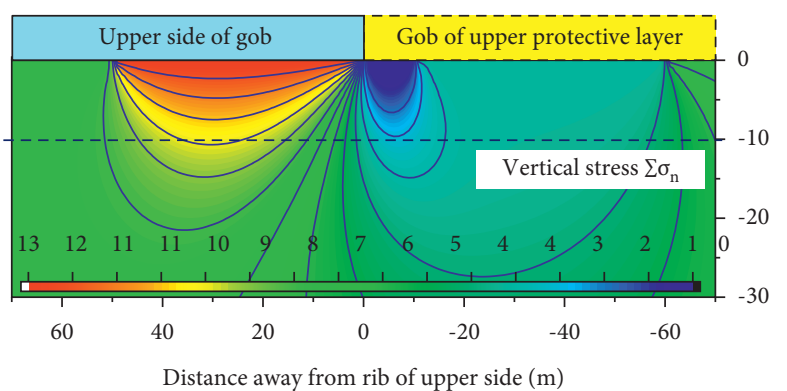

(a)

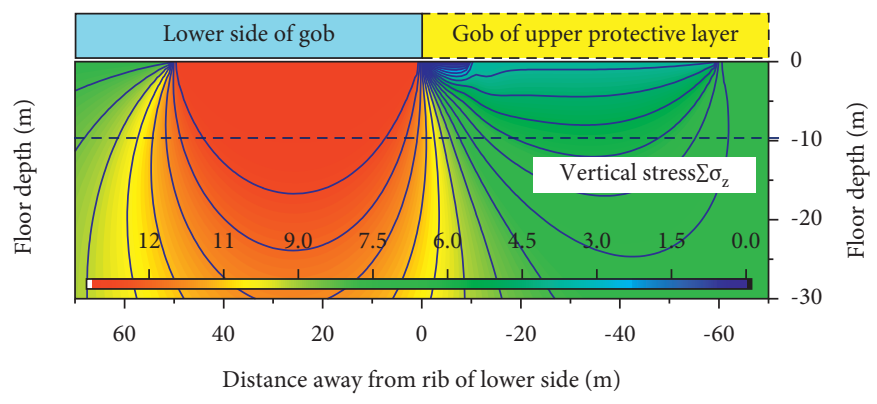

(b)

FIGURE 6: Contour map of vertical stress in the floor of gob of the upper protective layer. (a) Vertical stress in the floor of the upper side and (b) vertical stress in the floor of the lower side.

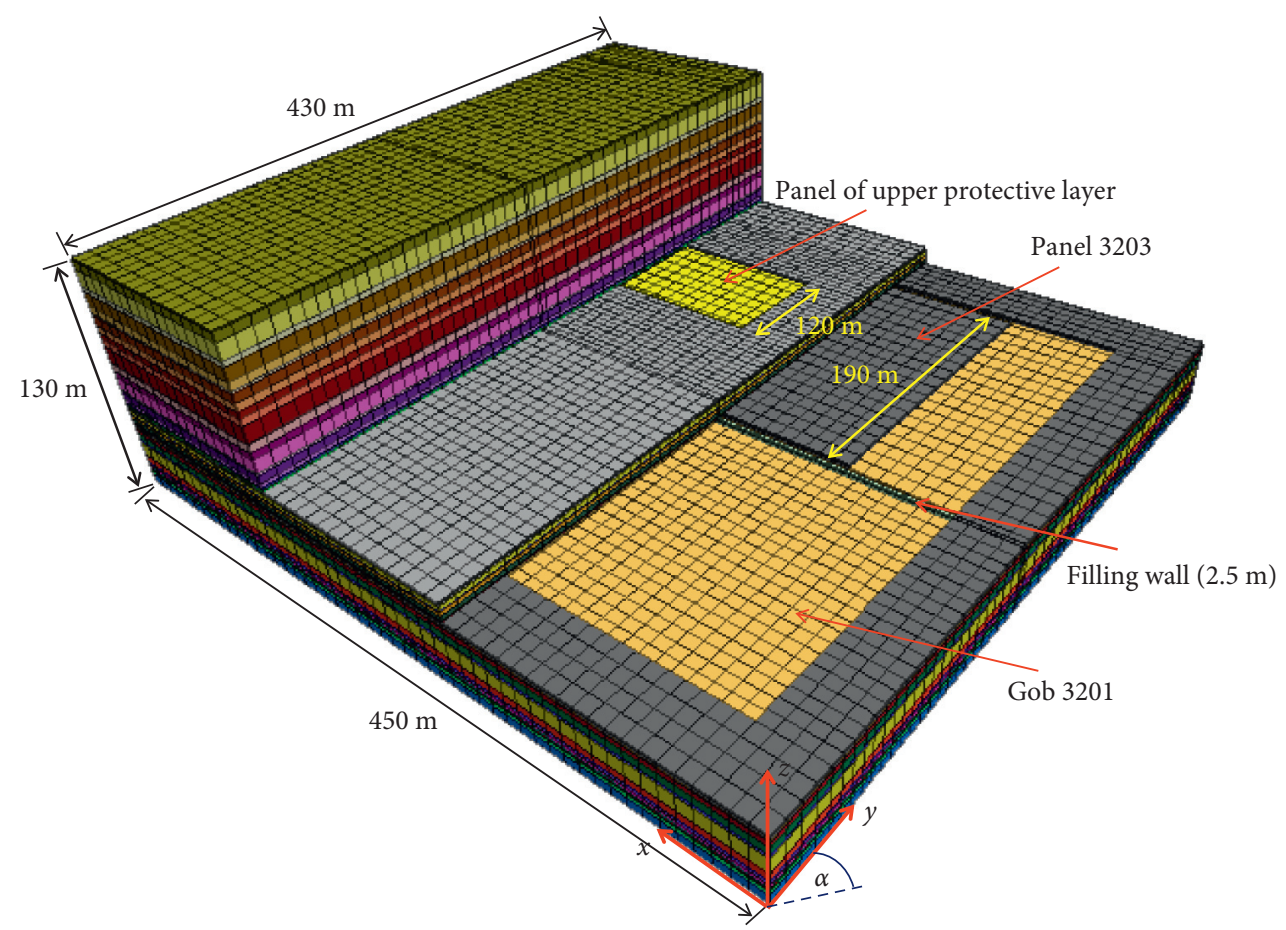

Figure 7: A flac ${ }^{3 \mathrm{~d}}$ model.

TABLe 1: The coal seam and strata assignment parameters of this 3D model.

\begin{tabular}{|c|c|c|c|c|c|c|}
\hline Types & $\begin{array}{l}\text { Density } \\
\left(\mathrm{kg} \cdot \mathrm{m}^{-3}\right)\end{array}$ & $\begin{array}{l}\text { Bulk modulus } \\
\quad(\mathrm{GPa})\end{array}$ & $\begin{array}{l}\text { Shear modulus } \\
(\mathrm{GPa})\end{array}$ & $\begin{array}{c}\text { Cohesion } \\
(\mathrm{MPa})\end{array}$ & $\begin{array}{c}\text { Internal friction angle } \\
\left({ }^{\circ}\right)\end{array}$ & $\begin{array}{l}\text { Thickness } \\
(\mathrm{m})\end{array}$ \\
\hline $\begin{array}{l}\text { Mudstone fine } \\
\text { sandstone }\end{array}$ & 2600 & 16.3 & 13.8 & 9.8 & 26 & 18.5 \\
\hline Gritstone & 2690 & 19.5 & 20.5 & 14.3 & 31 & 23.0 \\
\hline Sandy mudstone & 2730 & 13.4 & 13.1 & 28.8 & 20 & 15.5 \\
\hline Fine sandstone & 2800 & 22.5 & 21.6 & 18.7 & 32 & 16.0 \\
\hline Mudstone & 2600 & 16.3 & 13.8 & 9.8 & 26 & 5.0 \\
\hline Coal seam \#1 & 1360 & 1.6 & 1.7 & 1.1 & 35 & 1.3 \\
\hline Sandy mudstone & 2730 & 13.4 & 13.1 & 28.8 & 20 & 10.3 \\
\hline Coal seam \#2 & 1360 & 1.6 & 1.7 & 1.1 & 35 & 2.2 \\
\hline Siltstone & 2650 & 17.8 & 18.1 & 15.2 & 27 & 9.5 \\
\hline Mudstone & 2600 & 16.3 & 13.8 & 9.8 & 26 & 15.5 \\
\hline Siltstone & 2650 & 17.8 & 18.1 & 15.2 & 27 & 13.2 \\
\hline
\end{tabular}


samples in the laboratory, and these coal and rock standard samples are obtained by sampling them in situ and finishing them in the laboratory. In addition, the strain softening constitutive model is adopted for the filling wall in this $3 \mathrm{D}$ model, and the relevant parameters such as bulk modulus, shear modulus, density, and uniaxial compressive strength are also based on the laboratory test results of standard specimens, and they are $1.9 \mathrm{GPa}, 1.5 \mathrm{GPa}, 1100 \mathrm{~kg} / \mathrm{m}^{3}$, and 14.7 MPa. The parameters such as cohesion and internal friction angle are obtained by trial and error method, that is, comparing the stress-strain curves of standard specimens by numerical simulation and laboratory test methods [18], when the two stress-strain curves are in good agreement, a group of optimal parameters of cohesion and internal friction angle varying with strain can be obtained, as shown in Table 2.

The calculation steps of this 3D model are as follows: (1) calculation of original rock stress; (2) excavation of 3201 tailgate and 3201 headgate; (3) mining of panel 3201; (4) gobside entry filling; (5) excavation of 3203 tailgate; (6) mining of panel 3203 (initial mining stage, the mining face is not below panel of upper protective layer); (7) continue mining of panel 3203 (normal mining stage, the mining face is below panel of upper protective layer).

4.2. Analysis of Numerical Simulation Results. According to the 3D model established in Figure 7, the stress disturbance of surrounding rock in mining space of panel 3203 when the panel of upper protective layer is located above the middle of panel 3203 and 3203 tailgate is numerically simulated. The two different layout schemes of panel of upper protective layer are shown in Figure 8.

4.2.1. Original Layout Scheme. According to the original layout scheme in Figure 8(a), it can be seen that the mining face of panel 3203 can be divided into two stages, namely stage I which is not within the influence of the gob of upper protective layer and stage II which is within the influence of the gob of upper protective layer. The two different mining stages of panel 3203 are shown in Figure 9.

According to the calculation steps of this $3 \mathrm{D}$ model presented earlier, the vertical stress distribution behaviors of cross section during stage I can be simulated when the mining face of panel 3203 advances to a distance of $90 \mathrm{~m}$, $180 \mathrm{~m}$, and $270 \mathrm{~m}$, as shown in Figure 10.

According to Figure 10, in the initial mining stage of panel 3203, namely stage I, because panel 3203 is far away from gob of upper protective layer, it is not affected by the abutment pressure of side direction, so the influence of gob of upper protective layer can be ignored, and the simulation research is only carried out for panel 3203. It can be seen that with the mining progress of panel 3203 , the superposition of abutment pressure of side direction of gob 3201 and advanced abutment stress of gob 3203 is easy to form L-shaped stress superposition area in the lower end of panel 3203. The maximum stresses, namely peak stresses, are $48.2 \mathrm{MPa}$, $50.5 \mathrm{MPa}$, and $49.4 \mathrm{MPa}$ in L-shaped stress superposition area when the mining face of panel 3203 advances to a
TABLE 2: A group of optimal parameters of cohesion and internal friction angle.

\begin{tabular}{lccccccc}
\hline Strain & 0 & 0.022 & 0.048 & 0.062 & 0.076 & 0.102 & 0.135 \\
\hline $\begin{array}{l}\text { Cohesion } \\
\begin{array}{l}\text { Internal friction } \\
\text { angle }\end{array}\end{array}$ & 3.3 & 3.1 & 2.9 & 2.5 & 2.1 & 1.7 & 1.3 \\
\hline
\end{tabular}

distance of $90 \mathrm{~m}, 180 \mathrm{~m}$, and $270 \mathrm{~m}$, respectively. The average maximum stress is about $49.4 \mathrm{MPa}$, compared with the original rock stress of $17.5 \mathrm{MPa}$, it is known that the maximum stress concentration coefficient is about 2.8 .

With the advance of panel 3203 , in addition to the L-shaped stress superposition area is formed, the advance of panel 3203 will also lead to filling wall of gob-side entry to bear high stress concentration. It can be seen from Figure 10 that the peak stress in filling wall moves forward synchronously with the advance of panel 3203 and basically remains near the lower end of panel 3203. Therefore, for the stage I, it is necessary to do a good job of pressure relief and strengthening support in the advanced section of gob-side entry (3203 tailgate) near gob 3201. Especially for 3203 tailgate, the filling wall of gob-side entry is only a width of $2.5 \mathrm{~m}$, so it is necessary to strengthen the supporting measures on the side of this filling wall and the subsequent mine pressure monitoring.

Similarly, according to the calculation steps of this 3D model presented above, the vertical stress distribution behaviors of cross section during stage II can be simulated when the mining face of panel 3203 is $0 \mathrm{~m}, 45 \mathrm{~m}$, and $90 \mathrm{~m}$ away from the boundary line of gob of upper protective layer, as shown in Figure 11.

According to Figure 11, in the medium-term mining stage of panel 3203, namely stage II, because panel 3203 is close to gob of upper protective layer, it will be affected by the abutment pressure of side direction, so the influence of gob of upper protective layer cannot be ignored, and the simulation research is also needs to consider the influence of gob of upper protective layer for panel 3203. It can be seen that with the mining progress of panel 3203, the L-shaped stress superposition area that is already formed in lower end of panel 3203 will increase further. The maximum stresses, namely peak stresses, are $68.8 \mathrm{MPa}$, 71.5 MPa, and 71.4 MPa in L-shaped stress superposition area when the mining face of panel 3203 is $0 \mathrm{~m}, 45 \mathrm{~m}$, and $90 \mathrm{~m}$ away from the boundary line of gob of upper protective layer, respectively. It can be seen that the maximum stress value is relatively small when the mining face of panel 3203 advances to the boundary line of gob of upper protective layer, and then it maintains at a stable maximum stress value as the mining face of panel 3203 is pushed under the upper protective layer.

The average maximum stress is about $70.6 \mathrm{MPa}$, compared with the original rock stress of $17.5 \mathrm{MPa}$, it is known that the maximum stress concentration coefficient is about 4.0. Meanwhile, the advance of panel 3203 will further lead to filling wall of gob-side entry to bear high stress concentration. According to the above numerical simulation results, the stress in the advanced segment of 3203 tailgate 


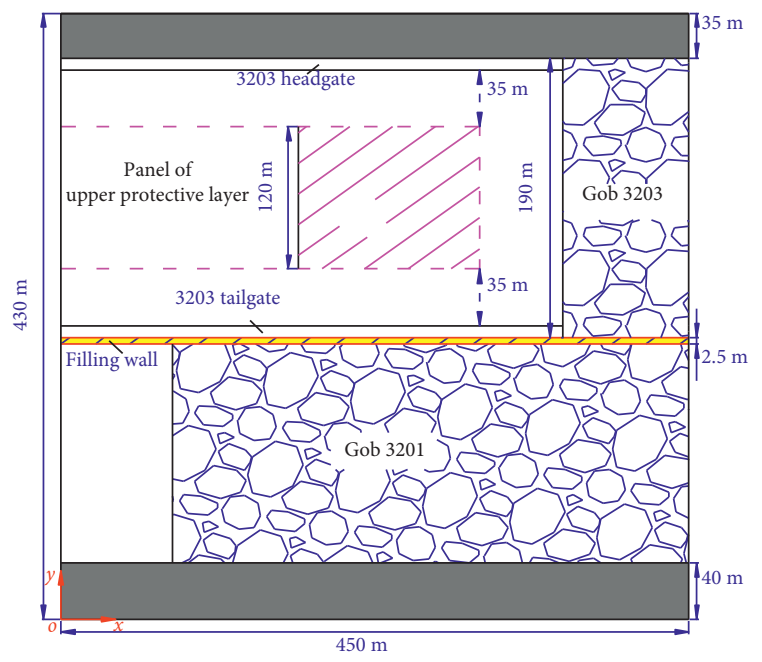

(a)

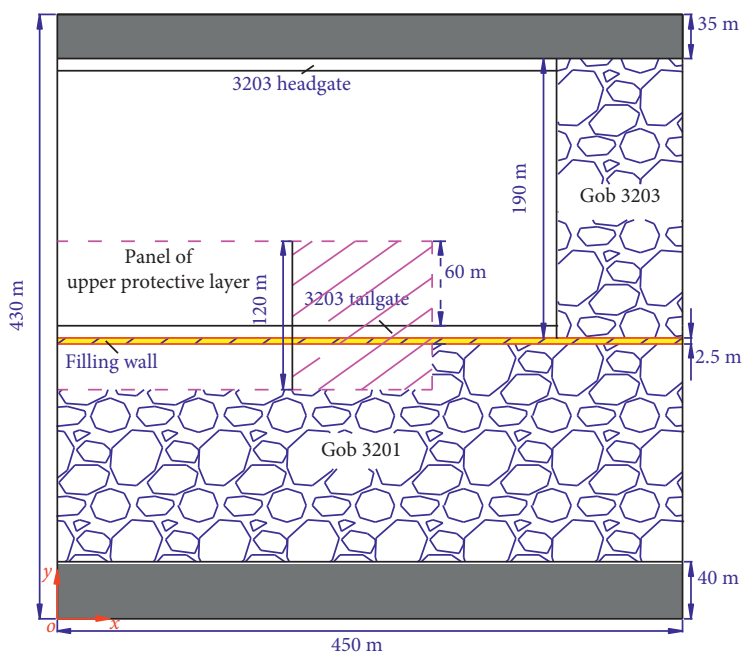

(b)

FIgURE 8: Two different layout schemes of panel of upper protective layer. (a) Original layout scheme; (b) optimal layout scheme.

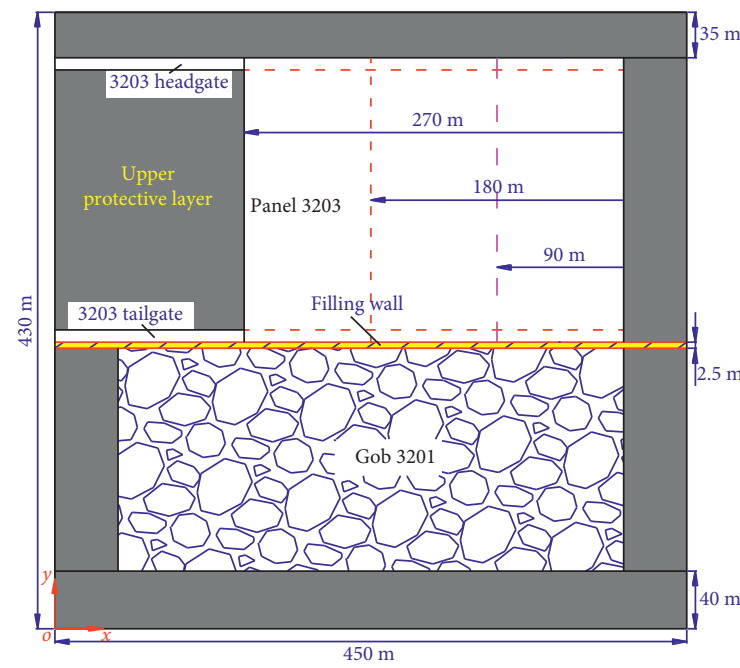

(a)

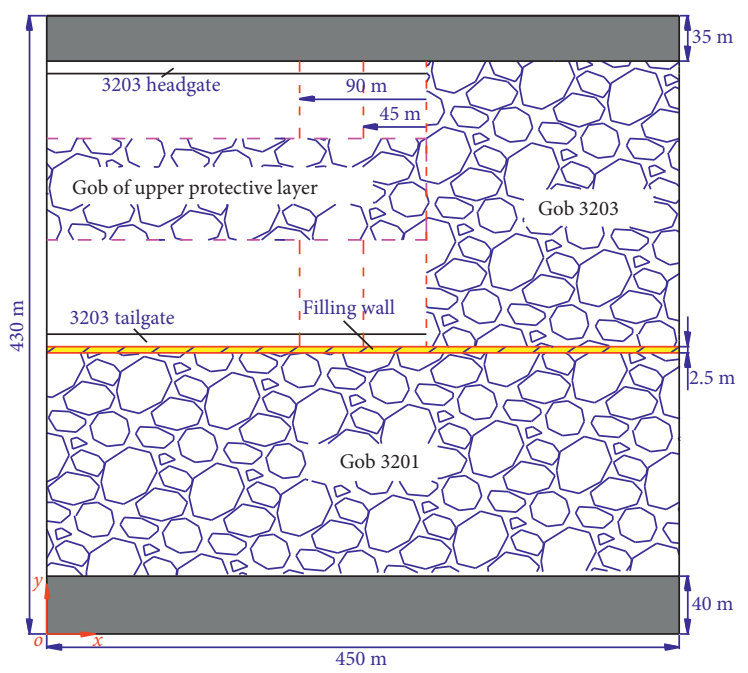

(b)

Figure 9: Two different mining stages of panel 3203. (a) Stage I; (b) stage II.

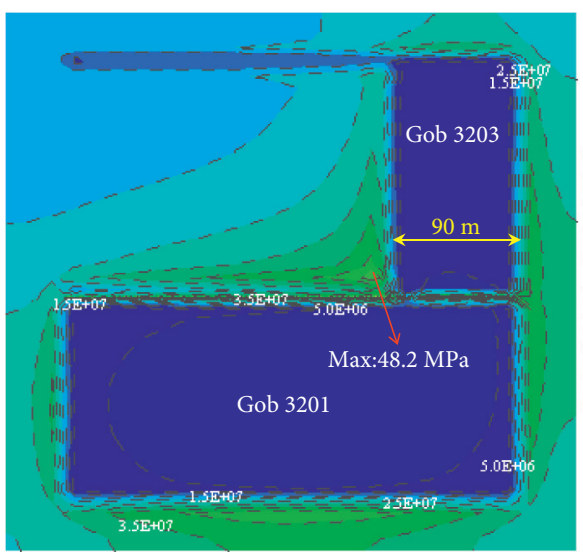

(a)

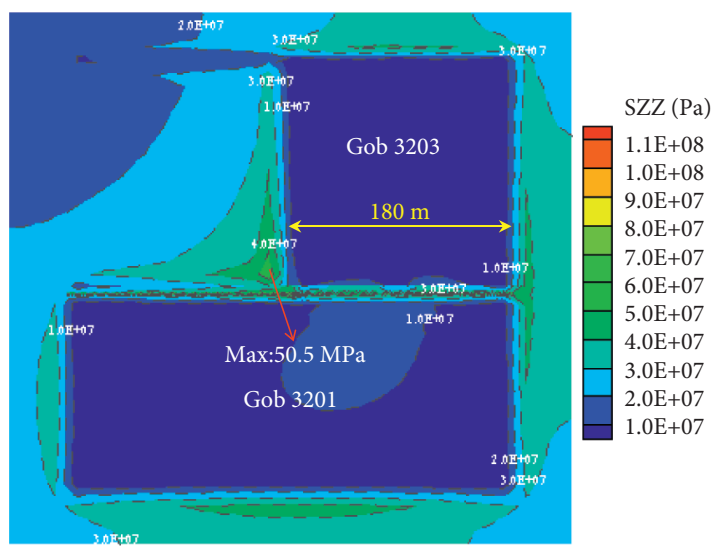

(b)

Figure 10: Continued. 


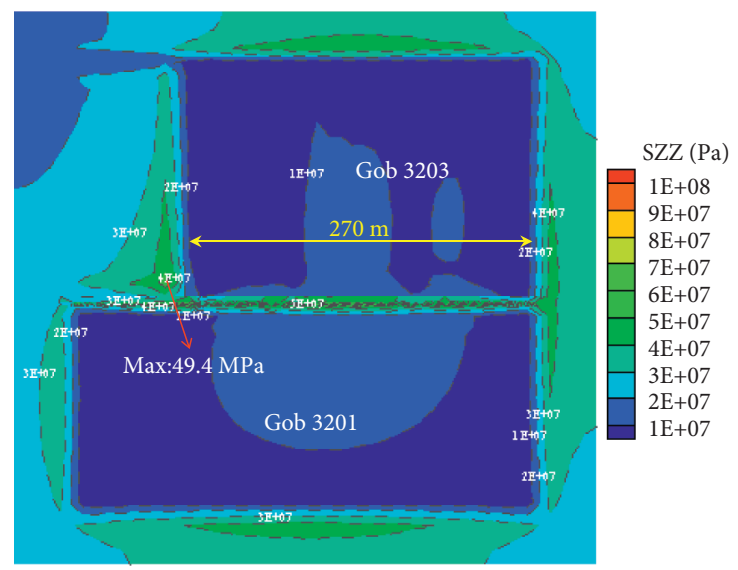

(c)

FIGURE 10: The vertical stress distribution behaviors of cross section during stage I. (a) The mining face of panel 3203 advances to a distance of $90 \mathrm{~m}$, (b) the mining face of panel 3203 advances to a distance of $180 \mathrm{~m}$, (c) the mining face of panel 3203 advances to a distance of $270 \mathrm{~m}$.

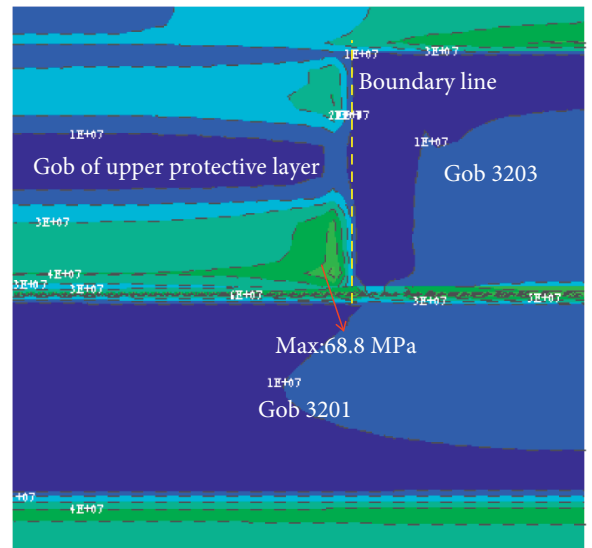

(a)

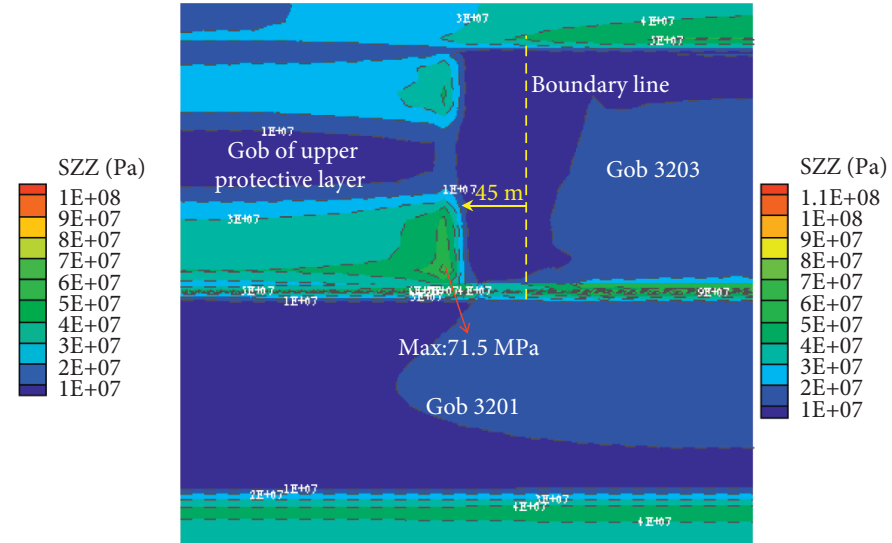

(b)

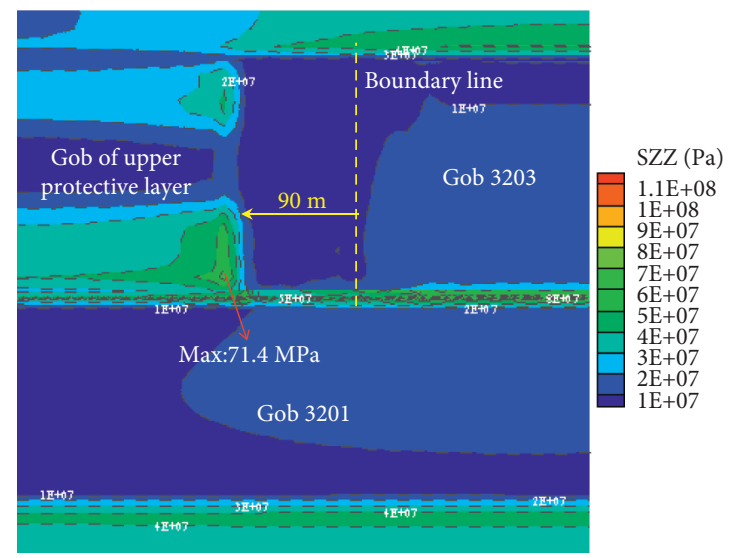

(c)

FIgURE 11: The vertical stress distribution behaviors of cross section during stage II. (a) The mining face of panel 3203 is $0 \mathrm{~m}$ away from boundary line, (b) the mining face of panel 3203 is $45 \mathrm{~m}$ away from boundary line, (c) the mining face of panel 3203 is $90 \mathrm{~m}$ away from boundary line.

can be analyzed, and the stress conditions of advanced segment of 3203 tailgate are shown in Figure 12.

According to Figure 12, it can be seen that the maximum stress concentration coefficient $\left(n_{x}\right)$ has to do with how many different stresses are superimposed, and the larger the stress concentration coefficient is, the greater the compressive stress of L-shaped stress superposition area is. Based on the theory of combined dynamic and static loads $[19,20]$, 


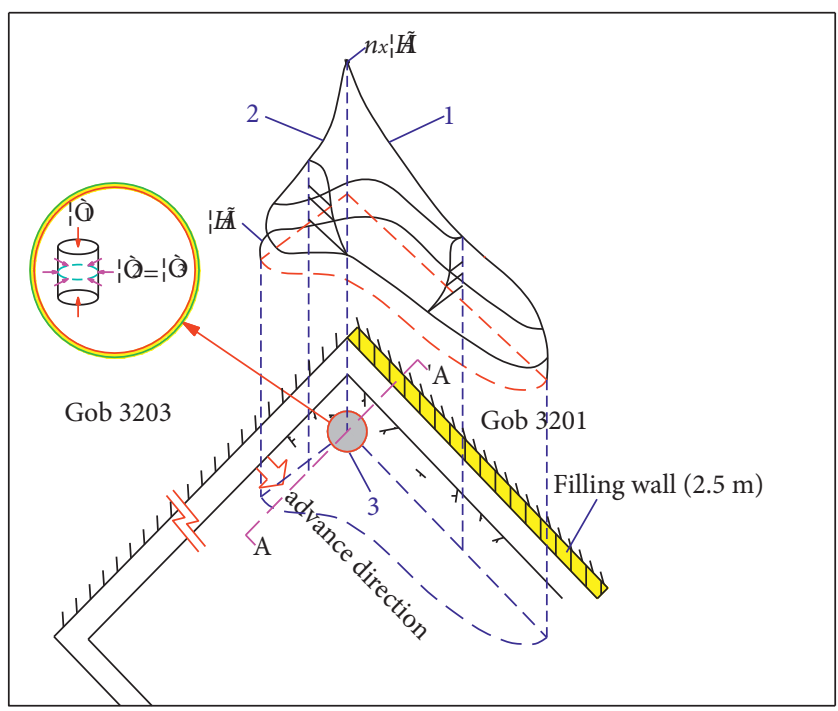

(a)

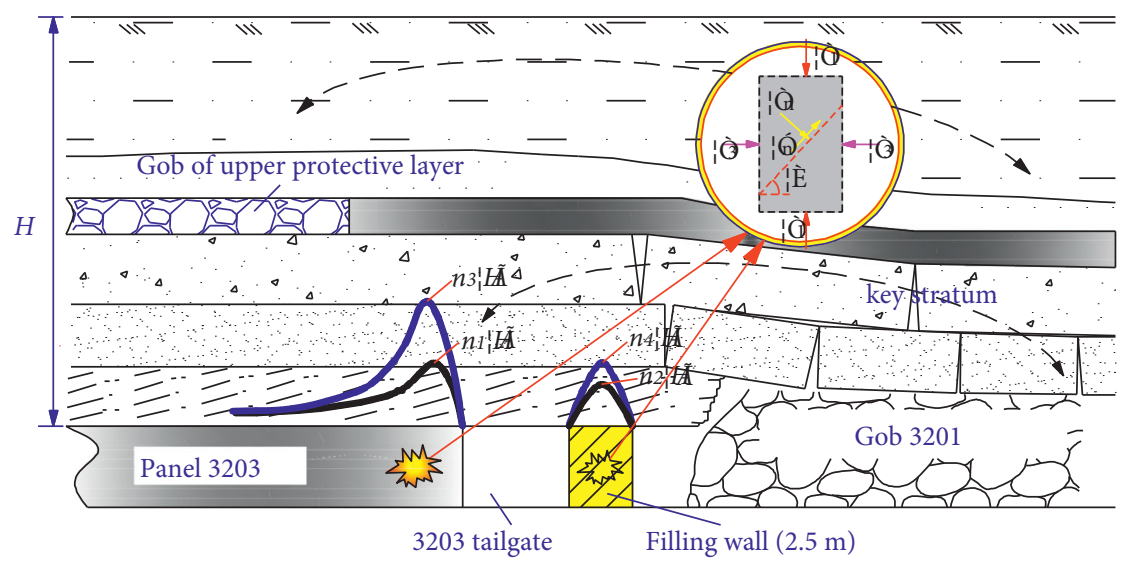

(b)

FIGURE 12: Mechanical model of surrounding rock stress conditions in advanced segment of 3203 tailgate. (a) Spatial diagram of L-shaped stress superposition area; (b) A-A' cross section. Note: 1-advanced abutment stress of gob 3203; 2-abutment pressure of side direction of gob 3201; 3-rock burst start-up zone.

when the superimposed stress value reaches a certain value, namely the maximum stress concentration coefficient $\left(n_{x}\right)$ is large, at this time a rock burst start-up zone will be formed in the surrounding rock of advanced segment of 3203 tailgate, and this rock burst start-up zone is easy to induce rock burst accidents during the mining period. According to the simulated results of Figures 10 and 11, it can be seen that the maximum stress concentration coefficient increases from 2.8 to 4.0 under the influence of gob of upper protective layer, the increase is as high as $42.9 \%$. This means that there is a high concentrated static load in L-shaped stress superposition area, and this area can be easily activated and transformed into a rock burst start-up zone under the influence of mining disturbance.

Based on Thessaghi's theory, it can be known that the coal-rock mass of the floor will also be affected by the vertical compressive stress caused by L-shaped stress superposition area. At the same time, the horizontal tectonic stress will cause the horizontal compression effect on the coal-rock mass of the floor. In the superposition of vertical compressive stress and horizontal tectonic stress, the floor is in an unstable state, and it is easy to have serious heaving floor or even floor rock burst accident during the mining period of panel 3203. According to the surrounding rock failure of advanced segment about 3203 tailgate on-site as shown in Figure 2, the correctness of the above numerical simulation results and theoretical analysis is also verified.

4.2.2. Optimal Layout Scheme. According to the optimal layout scheme in Figure 8(b), it also can be seen that the mining face of panel 3203 can be divided into two stages, namely stage I which is not within the influence of the gob of upper protective layer and stage II which is within the influence of the gob of upper protective layer. The two different mining stages of panel 3203 are shown in Figure 13.

According to the calculation steps of this $3 \mathrm{D}$ model presented above, the vertical stress distribution behaviors of cross section during stage I can be simulated when the 


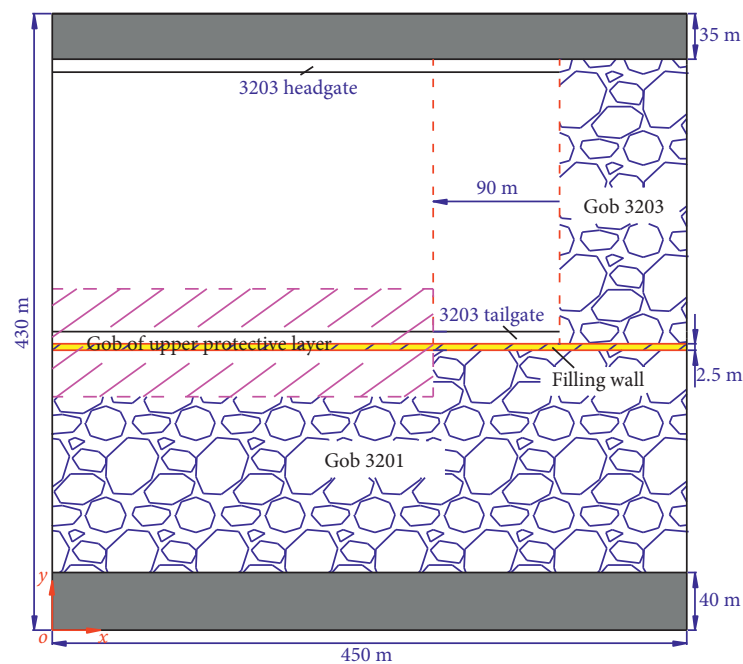

(a)

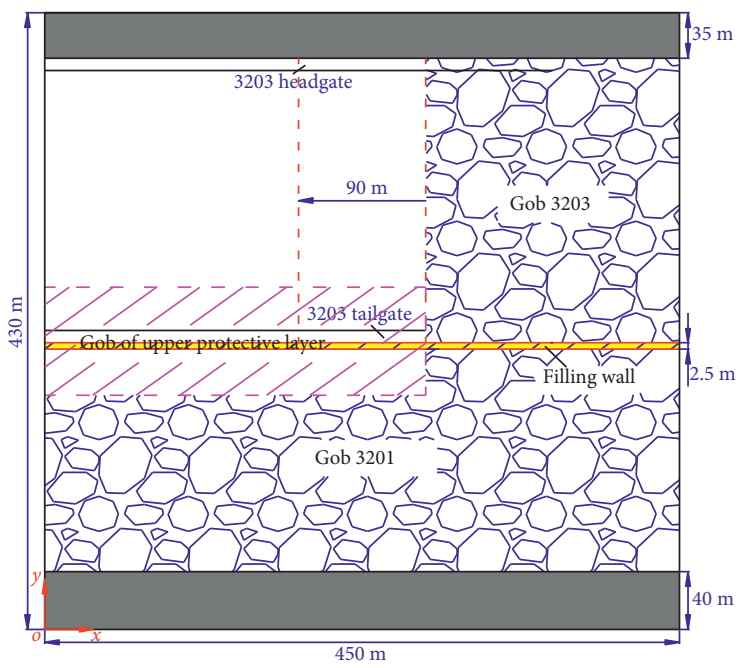

(b)

Figure 13: Two different mining stages of panel 3203 after optimizing the layout scheme. (a) Stage I; (b) stage II.

mining face of panel 3203 is $90 \mathrm{~m}$ away from the boundary line of gob of upper protective layer, as shown in Figure 14.

According to Figure 14, in the initial mining stage of panel 3203 after optimizing the layout scheme, namely stage I, because panel 3203 is far away from gob of upper protective layer, it is not affected by the abutment pressure of side direction, so the influence of gob of upper protective layer can be ignored. The maximum stress, namely peak stresses, is about $50.3 \mathrm{MPa}$ in L-shaped stress superposition area when the mining face of panel 3203 is $90 \mathrm{~m}$ away from the boundary line of gob of upper protective layer. Compared with the original rock stress of $17.5 \mathrm{MPa}$, it is known that the maximum stress concentration coefficient is about 2.9. Therefore, for this stage I after optimizing the layout scheme, it is also necessary to do a good job of pressure relief and strengthening support in the advanced section of gob-side entry (3203 tailgate) near gob 3201. Especially for 3203 tailgate, the filling wall of gob-side entry is only a width of $2.5 \mathrm{~m}$, so it is necessary to strengthen the supporting measures on the side of this filling wall and the subsequent mine pressure monitoring.

Similarly, according to the calculation steps of this $3 \mathrm{D}$ model presented above, the vertical stress distribution behaviors of cross section during stage II can be simulated when the mining face of panel 3203 is $0 \mathrm{~m}$ and $90 \mathrm{~m}$ away from the boundary line of gob of upper protective layer, as shown in Figure 15.

According to Figure 15, in the medium-term mining stage of panel 3203 after optimizing the layout scheme, namely stage II, because panel 3203 is under the influence of gob of upper protective layer, it will be affected by the pressure released zone caused by gob of upper protective layer, and the original L-shaped stress superposition area in lower end no longer exists. A new stress superposition area is formed at middle to lower end part of advance mining face of panel 3203. The maximum stresses, namely peak stresses, are $42.6 \mathrm{MPa}$ and $42.5 \mathrm{MPa}$ in this new stress superposition area when the mining face of panel 3203 is $0 \mathrm{~m}$

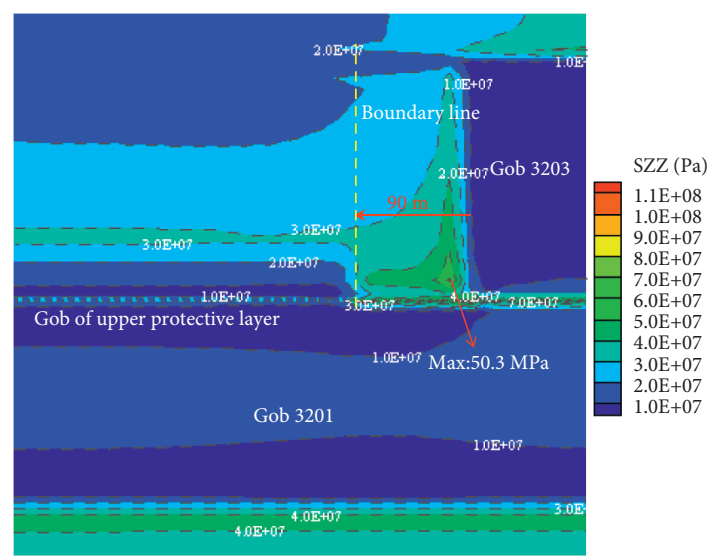

Figure 14: The vertical stress distribution behaviors of cross section after optimizing the layout scheme during stage I.

and $90 \mathrm{~m}$ away from the boundary line of gob of upper protective layer, respectively. It can be seen that the maximum stress value is relatively small when the mining face of panel 3203 advances to the boundary line of gob of upper protective layer, and then it maintains at a stable maximum stress value as the mining face of panel 3203 is pushed under the upper protective layer. The average maximum stress is about $42.6 \mathrm{MPa}$, compared with the original rock stress of $17.5 \mathrm{MPa}$, it is known that the maximum stress concentration coefficient is about 2.4. This shows that when the gob of upper protective layer is located above the 3203 tailgate, the original L-shaped stress superposition area is gone due the transfer and release of stress, which further optimizes the surrounding rock stress environment of advanced segment of 3203 tailgate, and is not easy to have high stress concentration in advanced segment of 3203 tailgate. At the same time, this optimal layout scheme can control the economic cost of support, which is of great significance for the safety of follow-up mining. 


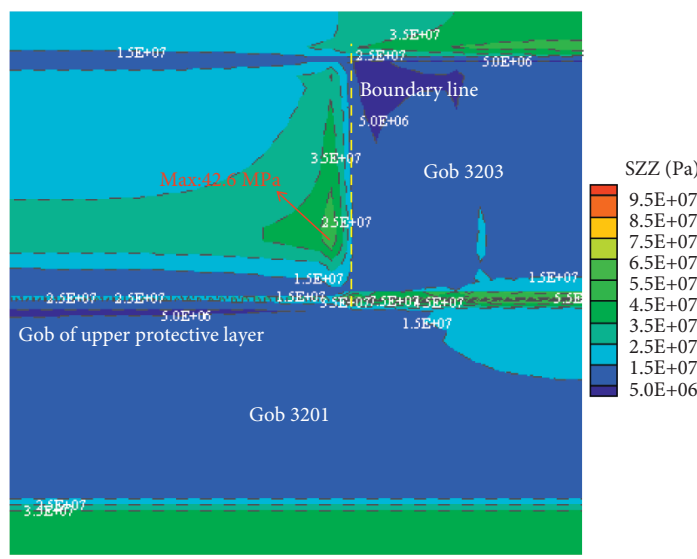

(a)

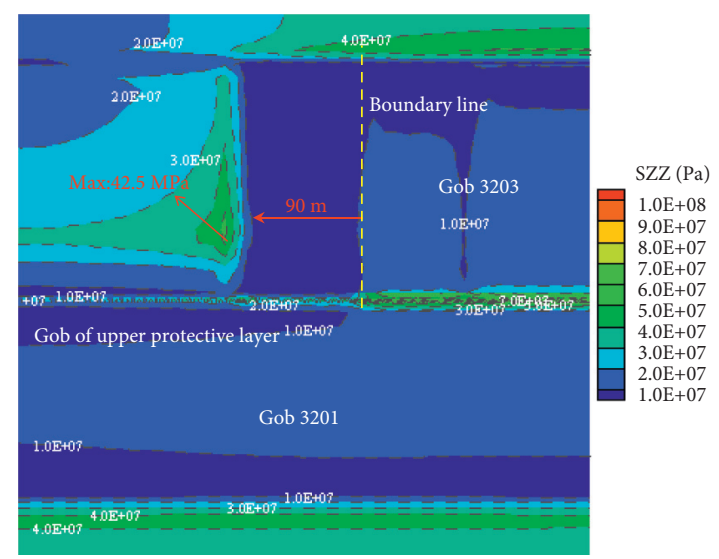

(b)

Figure 15: The vertical stress distribution behaviors of cross section after optimizing the layout scheme during stage II. (a) The mining face of panel 3203 is $0 \mathrm{~m}$ away from boundary line; (b) the mining face of panel 3203 is $90 \mathrm{~m}$ away from boundary line.

It can be seen that through the reasonable layout of the gob of upper protective layer, the stress environment of the surrounding rock in the advanced segment of 3203 tailgate can be effectively improved during stage II, which has a very significant effect on the prevention and control of the subsequent rock burst accidents.

\section{On-Site Industrial Applications}

During the mining period of panel 3205, which is an adjacent panel of panel 3203, the panel of upper protective layer is arranged just above the 3205 tailgate based on the optimal layout scheme. According to roof dynamic online monitoring system of type KJ216 installed on the hydraulic supports, the working resistance data of panel 3205 are monitored during the whole mining period, and 6 groups of "cross-shaped" measuring stations are set in 3205 tailgate to monitor the deformation of surrounding rock in the advanced segment of 3205 tailgate.

5.1. Working Resistance Monitoring Results of Hydraulic Support. The evolution laws of working resistance monitoring contour of hydraulic supports with the advancing of panel 3205 are shown in Figure 16.

According to Figure 16, it can be seen that the mining face of panel 3205 can be divided into two stages, namely stage I which is not within the influence of the gob of upper protective layer and stage II which is within the influence of the gob of upper protective layer. In the stage I, with the mining of panel 3205, when the mining face of panel 3205 is in the influence area of first weighting (data interval: 2017/6/ 14 2017/11/18) and influence area of the first square (data interval: 2018/4/30 2018/6/9), the working resistance of hydraulic supports in the mining face of panel 3205 is higher as a whole, and the working resistance of hydraulic supports in the lower side of mining face near 3205 tailgate is higher than that in the upper side near 3205 headgate. In the stage II, when panel 3205 is under the influence of gob of upper protective layer, the working resistance of hydraulic supports in the lower side of mining face of panel 3205 near 3205 tailgate is lower, while the working resistance of hydraulic supports in the middle area of mining face of panel 3205 is higher, which is consistent with the numerical simulation results. It shows that after the optimization and adjustment of the layout of the panel of upper protective layer, the overall stress environment of the surrounding rock in the advanced segment of 3205 tailgate can be effectively improved.

\subsection{Monitoring Results of Surrounding Rock Deformation in} Advanced Segment of 3205 Tailgate. During the mining period of panel 3205, 6 groups of "cross-shaped" measuring stations [21] are set in 3205 tailgate. Among them, 3 groups of "cross-shaped" measuring stations are set outside the influence of gob of upper protective layer and can be sequentially numbered group \#1, group \#2, and group \#3, and the interval between two adjacent measuring stations is about $50 \mathrm{~m}$; the other 3 groups of "cross-shaped" measuring stations are set within the influence of gob of upper protective layer and can be sequentially numbered group \#4, group \#5, and group \#6, and the interval between two adjacent measuring stations is also about $50 \mathrm{~m}$. The average values of monitoring results about measuring stations outside and within the influence of gob of upper protective layer are both shown in Figure 17.

According to Figure 17, it can be seen that when the 3205 tailgate is not within the influence of gob of upper protective layer (stage I), the measuring stations begin to be affected by advanced abutment stress at $45 \mathrm{~m}$ away from the mining face of panel 3205, and the maximum convergence of roof to floor is about $411 \mathrm{~mm}$, and the maximum convergence of two ribs is about $379 \mathrm{~mm}$; it also can be seen that when the 3205 tailgate is within the influence of gob of upper protective layer (stage II), the measuring stations begin to be affected by advanced abutment stress at $35 \mathrm{~m}$ away from the mining face of panel 3205, and the maximum convergence of roof to floor is about $147 \mathrm{~mm}$, and the maximum convergence of two ribs is about $129 \mathrm{~mm}$. By comparing the average values of monitoring results in advanced segment of 3205 tailgate of the two stages (stage I and stage II), it can be seen that the 


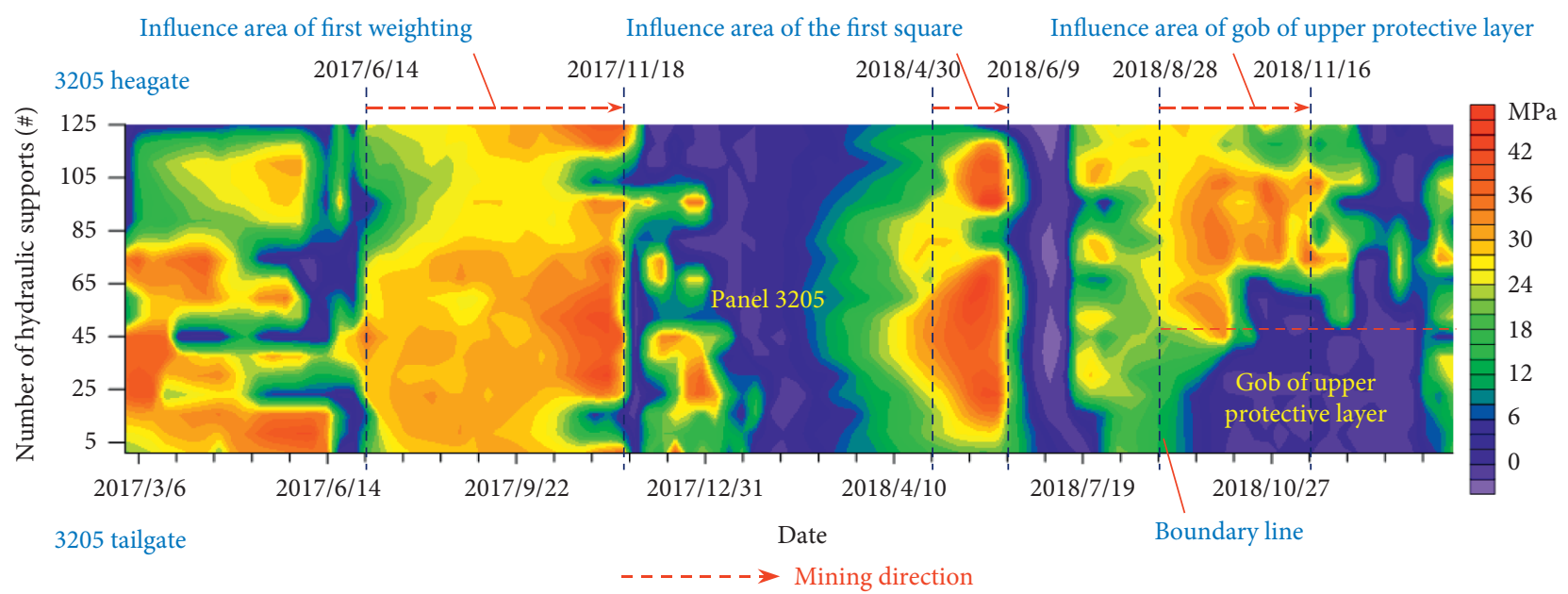

FIGURE 16: Working resistance monitoring contour of hydraulic supports.

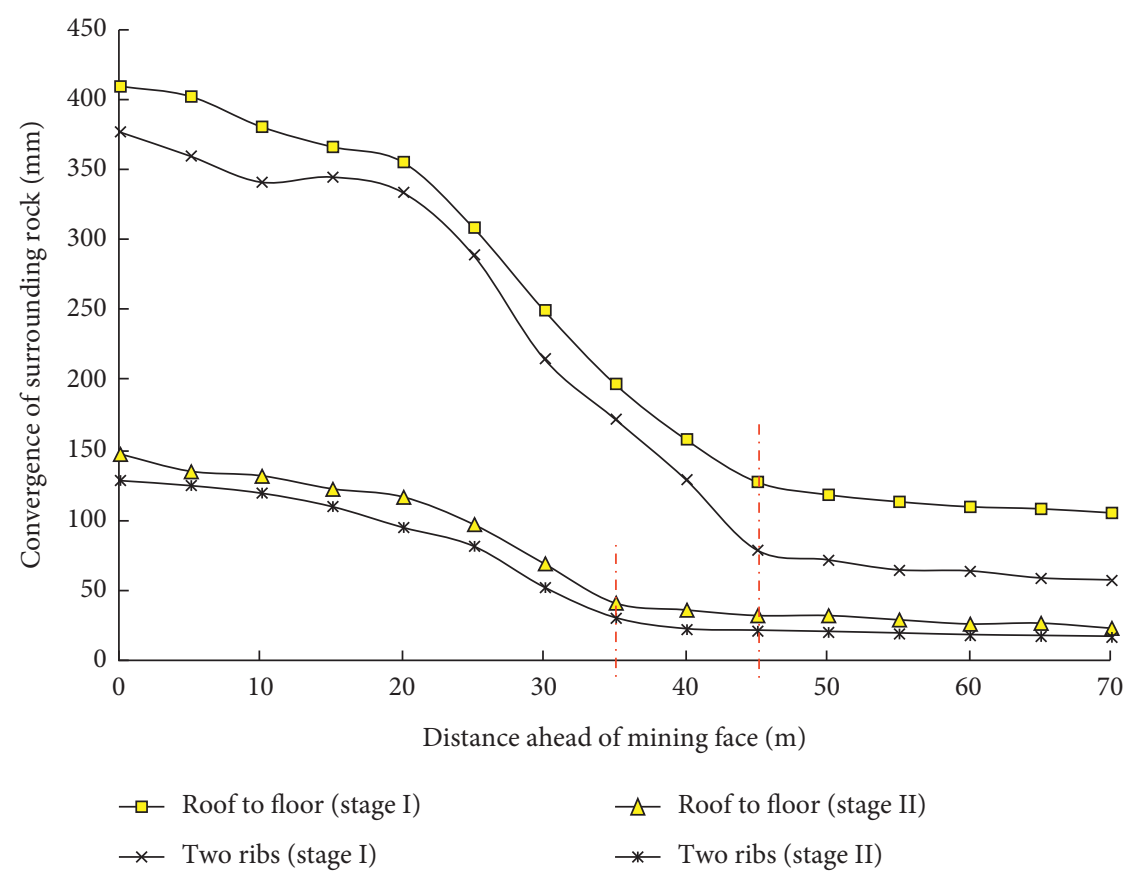

Figure 17: The average values of monitoring results in advanced segment of 3205 tailgate.

maximum convergence decreasing amplitudes of roof to floor and two ribs are $64.2 \%$ and $66.0 \%$ respectively, and the influence range of advanced abutment stress is reduced by $10 \mathrm{~m}$ at the same time. After the optimization and adjustment of the layout of the panel of upper protective layer, the overall deformation of surrounding rock is small, and the stress environment of surrounding rock is good, which indicates that the overall pressure relief of surrounding rock in advanced segment of 3205 tailgate can be effectively realized.

\section{Conclusions}

(1) Based on the field investigation results about advanced segment of 3203 tailgate, it can be seen that although the panel of upper protective layer can reduce the risk of panel 3203 affected by gas disaster, but it has no effect on improving the stress environment of surrounding rock. Even the mine pressure behaviors of surrounding rock and filling wall are in a poor stress environment.

(2) Taking the upper protective layer of panel 3203 as the engineering background, a simplified mechanical model of abutment pressure of side direction on both sides of gob is established. According to contour map of vertical stress in the floor of gob of upper protective layer, it can be seen that the overall stress environment of the floor under the gob of upper protective layer is good, and the overall stress environment of the floor under the upper side of gob is also good, but the overall stress environment of the floor under the lower side of gob is bad. 
(3) According to the relative position relation of panel 3203 and its panel of upper protective layer, a Flac $^{3 \mathrm{D}}$ model is established, and two different layout schemes of panel of upper protective layer are simulated. Under the original layout scheme conditions, it can be seen that with the mining progress of panel 3203, the superposition of abutment pressure of side direction of gob 3201 and advanced abutment stress of gob 3203 is easy to form L-shaped stress superposition area in the lower end of panel 3203. The maximum stress concentration coefficient is about 2.8 for the stage I, and the maximum stress concentration coefficient is about 4.0 for the stage II. The maximum stress concentration coefficient increases from 2.8 to 4.0 under the influence of gob of upper protective layer, the increase is as high as $42.9 \%$. This means that the L-shaped stress superposition area can be easily activated and transformed into a rock burst start-up zone under the influence of mining disturbance.

(4) Under the optimal layout scheme conditions, it can be seen that with the mining progress of panel 3203, a new stress superposition area is formed at the middle to lower end part of advance mining face of panel 3203 for the stage II, and the maximum stress concentration coefficient is about 2.4. The original L-shaped stress superposition area is gone due the transfer and release of stress, which further optimizes the surrounding rock stress environment of advanced segment of 3203 tailgate, and the optimal layout scheme has a very significant effect on the prevention and control of the subsequent rock burst accidents.

(5) According to on-site industrial applications, a variety of monitoring methods are used to verify the optimal layout scheme. In the stage II, when panel 3205 is under the influence of gob of upper protective layer, the working resistance of hydraulic supports in the lower side of mining face of panel 3205 near 3205 tailgate is lower. The maximum convergence decreasing amplitudes of roof to floor and two ribs are $64.2 \%$ and $66.0 \%$, respectively, and the influence range of advanced abutment stress is reduced by $10 \mathrm{~m}$ at the same time. These monitoring results indicate that the overall pressure relief of surrounding rock in advanced segment of 3205 tailgate can be effectively realized.

\section{Data Availability}

All the data used to support the findings of this study are included within the article, and there are not any restrictions on data access.

\section{Conflicts of Interest}

The authors declare no conflicts of interest.

\section{Acknowledgments}

The work was supported by the Key Project of National Natural Science Foundation of China (No. 51634001) and the National Natural Science Foundation of China (Nos. 51574243, 51404269, and 51674253).

\section{References}

[1] W. Cai, L. M. Dou, G. Y. Si et al., "A new seismic-based strain energy methodology for coal burst forecasting in underground coal mines," International Journal of Rock Mechanics and Mining Sciences, vol. 123, no. 5, pp. 1-11, 2019.

[2] Z. Yang, C. Liu, S. Tang, L. Dou, and J. Cao, "Rock burst mechanism analysis in an advanced segment of gob-side entry under different dip angles of the seam and prevention technology," International Journal of Mining Science and Technology, vol. 28, no. 6, pp. 891-899, 2018.

[3] Z. Q. Yang, C. Liu, F. S. Li et al., "The mechanism and application of high-pressure water jet technology to prevent compound dynamic disaster," Arabian Journal of Geosciences, vol. 14, no. 13, pp. 1-20, 2021.

[4] P. Sun, H. T. Sun, F. J. Lin et al., "Experimental study on the ratio model of similar materials in the simulation test of coal and gas outburst," Scientific Reports, vol. 11, no. 1, pp. 1-14, 2021.

[5] X. H. Tian, D. Z. Song, X. Q. He et al., "Investigation on micro-surface adhesion of coals and implications for gas occurrence and coal and gas outburst mechanism," Journal of Natural Gas Science and Engineering, vol. 94, no. 5, pp. 1-12, 2021.

[6] L. M. Dou, J. He, A. Y. Cao et al., "Rock burst prevention methods based on theory of dynamic and static combined load induced in coal mine," Journal of China Coal Society, vol. 40, no. 7, pp. 298-310, 2015.

[7] J. F. Pan, Y. Ning, D. B. Mao et al., "Theory of rock burst startup during coal mining," Chinese Journal of Rock Mechanics and Engineering, vol. 31, no. 3, pp. 586-596, 2012.

[8] J. F. Pan, Y. Ning, Z. H. Qin et al., "Dredging technology of pressure with deep-hole interval blasting based on theory of rock burst start-up," Chinese Journal of Rock Mechanics and Engineering, vol. 31, no. 7, pp. 1414-1421, 2012.

[9] Y. X. Zhao, J. L. Zhou, W. G. Liu et al., "Characteristics of ground pressure and mechanism of coal burst in the gob side roadway at Xinjie deep mining area," Journal of China Coal Society, vol. 45, no. 5, pp. 1595-1606, 2020.

[10] Y. D. Jiang, H. H. Song, Z. Q. Ma et al., "Optimization research on the width of narrow coal pillar along goaf tunnel in tectonic stress zone," Journal of China Coal Society, vol. 43, no. 2, pp. 319-326, 2018.

[11] S. T. Zhu, B. Wang, F. X. Jiang et al., "Study on reasonable width of isolated coal pillar based on rock burst-mine earthquake coordinated control," Coal Science and Technology, vol. 49, no. 6, pp. 102-110, 2021.

[12] J. Ma, C. Hou, J. Hou et al., "Numerical and similarity simulation study on the protection effect of composite protective layer mining with gently inclined thick coal seam," Shock and Vibration, vol. 2021, pp. 1-15, 2021.

[13] W. Wang, Y. P. Cheng, L. Yuan et al., "Floor fracture evolution and relief gas drainage timeliness in deeper underground short-distance upper protective coal seam extraction," Journal of China Coal Society, vol. 41, no. 1, pp. 138-148, 2016. 
[14] K. Noack, "Control of gas emissions in underground coal mines," International Journal of Coal Geology, vol. 35, no. 1, pp. 57-82, 1998.

[15] Z.-Q. Yang, C. Liu, G.-A. Wang, G.-W. Li, and F.-S. Li, "Structural characteristics analysis of overlying rocks and prevention measures with a long-wall face passing across abandoned roadways: a case study," Shock and Vibration, vol. 2021, pp. 1-15, 2021.

[16] G. C. Zhang, L. J. Chen, Z. J. Wen et al., "Squeezing failure behavior of roof-coal masses in a gob-side entry driven under unstable overlying strata," Energy Science \& Engineering, vol. 8, no. 7, pp. 2443-2456, 2020.

[17] G. A. Zhu, L. M. Dou, Z. L. Li et al., "Mining-induced stress changes and rock burst control in a variable-thickness coal seam," Arabian Journal of Geosciences, vol. 5, no. 9, pp. 365-376, 2016.

[18] G. C. Zhang, C. W. Zang, M. Chen et al., "Ground response of entries driven adjacent to a retreating longwall panel," International Journal of Rock Mechanics and Mining Sciences, vol. 138, no. 11, pp. 1-12, 2021.

[19] L. M. Dou and X. Q. He, Theory and Technology of Rock Burst Prevention, pp. 40-65, China University of Mining and Technology Press, Xuzhou, China, 2001.

[20] L. M. Dou, J. Z. Bai, X. W. Li et al., "Study on prevention and control technology of rockburst disaster based on theory of dynamic and static combined load," Coal Science and Technology, vol. 46, no. 10, pp. 1-8, 2018.

[21] M. Hu, W. Zhao, Z. Lu, J. Ren, and Y. Miao, "Research on the reasonable width of the waterproof coal pillar during the mining of a shallow coal seam located close to a reservoir," Advances in Civil Engineering, vol. 2019, pp. 1-14, 2019. 